\title{
MEASUREMENTS OF THE $E$ REGION NEUTRAL WIND FIELD
}

\author{
L. L. COGGER and J. S. MURPHREE \\ Department of Physics, The University of Calgary, Calgary, Alberta, Canada T2N 1N4 \\ and \\ C. A. TEPLEY* and J. W. MERIWETHER, JR. \\ Space Physics Research Laboratory, University of Michigan, Ann Arbor, MI 48109, U.S.A.
}

(Received 29 August 1984)

\begin{abstract}
The neutral E-region wind field was measured at Calgary, Canada $\left(51^{\circ} \mathrm{N}, 114^{\circ} \mathrm{W}\right)$ during 75 nights in 1982. Observations of the Doppler shift of the 5577- $\AA$ emission line of atomic oxygen using a Fabry-Perot interferometer were converted to horizontal wind vectors. From the analysis of the data, four categories of wind characteristics were identified. In order of increasing magnetic activity these categories are (a) wind field mostly variable in space and time, (b) predominantly equatorward flow throughout the night, (c) predominantly poleward flow throughout the night and (d) north-westward flow before midnight and southward after midnight. The wind magnitude was also variable and on some disturbed days exceeded $200 \mathrm{~m} \mathrm{~s}^{-1}$.
\end{abstract}

\section{INTRODUCTION}

One technique that has been successfully applied to the study of the dynamics of the Earth's upper atmosphere is the measurement of the Doppler shift of atomic lines with a Fabry-Perot interferometer. The specific objective of most experiments has been to investigate the neutral wind field in the upper thermosphere by measurements of the $6300-\AA$ line of atomic oxygen (Armstrong, 1969; Hays and Roble, 1971; Hernander. and Roble, 1976; Jacka et al., 1979; Rees et al., 1984; Burnside et al., 1981; Tepley et al., 1984; Killeen et al., 1982; Cocks and Jacka, 1979; and references therein). The wind field in the lower thermosphere is more complex to measure because of the importance of various tidal modes (Forbes and Garrett, 1979) and gravity waves (Hines, 1960) as well as electrodynamic effects (Rees, 1975) in the auroral zones. Various radio and radar techniques have been successfully applied to the study of $D$ and $E$ region dynamics (Evans, 1978; Manson et al., 1981). Rocket experiments have provided observations of the wind vector as a function of altitude (Heppner and Miller, 1982). In this paper we present the results from the medsurements of the Doppler shift of the 5577-A emission of atomic oxygen using a Fabry-Perot interferometer at Calgary, Canada $\left(51^{\circ} \mathrm{N}, 114^{\circ} \mathrm{W}\right)$. This line is emitted in the night airglow from the region of the peak of the atomic

* Present address: Arecibo Observatory, P.O. Box 995 , Arecibo, Puerto Rico 00613, U.S.A. oxygen layer as a result of chemical recombination reactions (Bates, 1979), and in the aurora as a consequence of electron precipitation. The altitude distribution of the emitting region is variable in aurora, but $115 \mathrm{~km}$ is a common altitude for the maximum emission rate(Rees, 1975). The instrument measures the total emission along the line of sight, so the Doppler shift that is measured is weighted by the distribution of the volume emission rate along that line of sight and therefore cannot separate the airglow and aurora components. Of course, when the aurora occurs it is generally intense enough to dominate completely the contribution from the airglow. Measurements were obtained for 75 nights between June and November, 1982. In the following sections of this paper we describe the experiment and the main features of the observed $E$ region neutral wind, and then briefly discuss some possible physical interpretations.

\section{OBSERVATIONS}

The interferometer and its automatic operating capability have deen described by Meriwether et al. (1983). It is essentially a pressure-controlled FabryPerot interferometer with $15-\mathrm{cm}$ diameter etalon plates separated by $1.0 \mathrm{~cm}$. A mirror system directs the $0.6-$ degree field of view to any point in the sky, and a $8-\AA$ interference filter rejects unwanted emissions from the instrument. All the observations were made using an image plane detector that was developed for the 
interferometer flown in the Dynamics Explorer-B satellite (Hays et al., 1981). The use of this detector eliminates the need to pressure scan the instrument because light is collected in 12 spectral channels simultaneously. Another significant advantage is that intensity variations need not be independently monitored because these variations do not distort the measured fringe profile as they can during a scan with a single detector. The photon-induced pulses are counted by 12 computer-controlled scalers and periodically stored, along with other relevant information, on a 20 megabyte hard disk.

The observing sequence used was similar to that described by Tepley et al. (1984) for $6300-\AA$ observations. A complete mirror cycle consisted of measurements at zenith angles of 0,45 and $70^{\circ}$ and azimuth angles of $0,45,135,225$ and $315^{\circ}$. The offcardinal points were used so that line-of-sight vectors from two different directions could be combined under the assumption that the Earth is rotating under a wind field that is fixed in space for the interval between the two measurements. This time interval for $110 \mathrm{~km}$ is 9 min at $45^{\circ}$ zenith angle and 24 min at $70^{\circ}$ zenith angle. During active aurora this assumption may not be satisfactory, but this is somewhat compensated by a shorter mirror cycle time because the integration period is terminated when a preset maximum count has been acquired. The number of mirror cycles per night varied with the length of the night and the amount of aurora present, but an average of about 40 , corresponding to 400 fringe measurements, was achieved.

The analysis of the data from each night required several steps. First, every fringe was fitted by a Gaussian function to yield the position of the fringe, the halfwidth of the fringe and the peak and background count rates. The zenith observations were used as the zerowind reference. In order to minimize the possible cffects of vertical motions such as Hernandez (1982) and Biondi (1984) have observed in the upper thermosphere, we fitted the zenith fringe positions for the entire night by a third-order polynomial function and used this function as the reference. When the fits were very good with this low order function, it was our conclusion that vertical winds were not affecting the data; but for nights when scatter about the fitted function was evident, we concluded that vertical winds could be significant and we eliminated the data for those nights. For the remaining nights, the line of sight spectral shifts of non-zenith observations were converted to horizontal velocity vectors in the observing azimuth direction assuming the wind to be entirely horizontal. Finally, the off-cardinal vectors were combined in pairs as described above to yield the average horizontal wind vector for a particular time interval. Therefore, the results from a night of measurements are sequences of neutral wind vectors obtained from regions of space centered on four latitudes, two South and two North of Calgary. In addition the North $70^{\circ}$ zenith angle observations were retained to provide an independent North-South component as far North of Calgary as possible.

Analysis of the approx. 30,000 fringes revealed significant day-to-day and even hour-to-hour variations in the wind vectors reflecting the expected variability in $E$ region dynamics. The most striking pattern in the $E$ region wind field was that obtained during periods of very high magnetic activity $\left(K_{p}\right.$ greater than 5 for several $3-\mathrm{h}$ periods). Figure 1 shows the observed pattern from 1 such night, $5 / 6$ September 1982. Of the 75 days analyzed 6 occurred during such conditions ( $K_{p}$ exceeding 8 at times), and the average wind field for 4 of these nights $(6 / 7$ August, 5/6 September, 20/21 September, 25/26 October) is shown in Fig. 2.

Comparison of Figs. 1 and 2 illustrates the consistency of the wind field on these 4 nights at all local times. Such a pattern is considerably different from the observations made during all other moderately disturbed and quiet days. The general flow pattern is evident in the figures: wind toward the Northwest until about 20.00 L.T.; mostly westward until about 23.00 , then shifted southward through to the end of the observations at about 04.00. The wind vector thus rotated counterclockwise from northwestward in the evening to southward in the morning. The magnetic declination at Calgary is $23^{\circ} \mathrm{E}$, so in magnetic co-ordinates the evening direction was initially close to due westward. The magnitude of the neutral wind at the altitude of the emission was near or somewhat above $100 \mathrm{~m} \mathrm{~s}^{-1}$ in the early evening and in the morning, and was between 50 and $100 \mathrm{~m} \mathrm{~s}^{-1}$ during the late evening. The wind speed on $5 / 6$ September was significantly larger than the average, particularly in the early evening and after 01.00 when it exceeded $200 \mathrm{~m} \mathrm{~s}^{-1}$ for periods of time. One other characteristic of the wind in the morning is that it increased in magnitude from North to South, that is from $53^{\circ}$ to near $50^{\circ}$ geographic (60-57 geomagnetic). This is more evident for $5 / 6$ September (Fig. 1) than for the average of the 4 nights. The northernmost vector in both figures shows only the North-South component of the wind because measurements were made at $0^{\circ}$ azimuth angle. This component is consistent with the other data: a northward component until 22.00-23,00, and a southward component thereafter.

The remaining 2 very disturbed days, 20/21 September and 13/14 October were different from the 
Universal Time

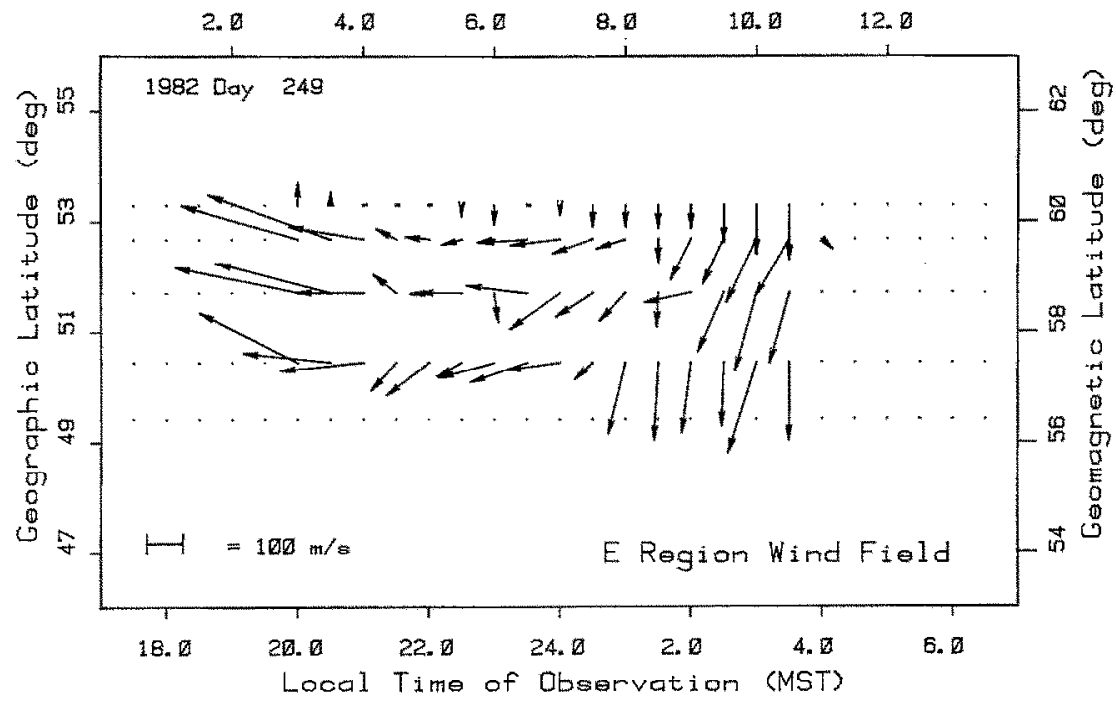

Fig. 1. Neutral horizonTal WIND vectors for 5/6 SePtember 1982.

Note that the most northern vectors are Norih-South components only in this and subsequent figures. The day number(s) on the figures refer to U.T.

other 4 in that the wind retained a northward component throughout the night. The westward component abated around 01.00 . The wind vector, of magnitude $50-100 \mathrm{~m} \mathrm{~s}^{-1}$, rotated clockwise from northwestward to northward.
The measurements from quiet and moderately disturbed days were examined and grouped according to the following general characteristics: Wind predominantly northward, wind predominantly southward, wind predominantly eastward after midnight

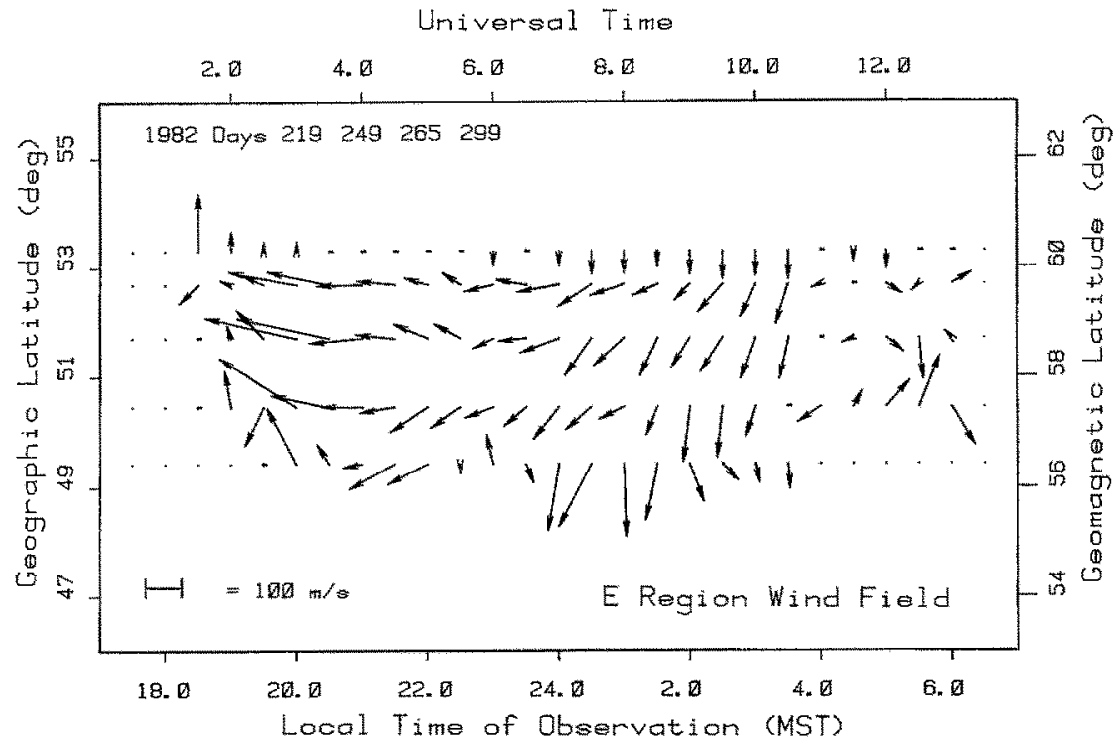

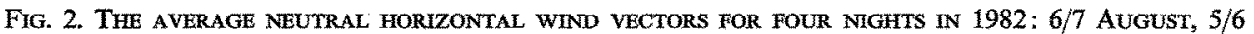
SEPTEMBER, 21/22 SEPTEMBER AND 25/26 OCTOBER.

These were all magnetically active periods with $K_{p} \geqslant 5$. 


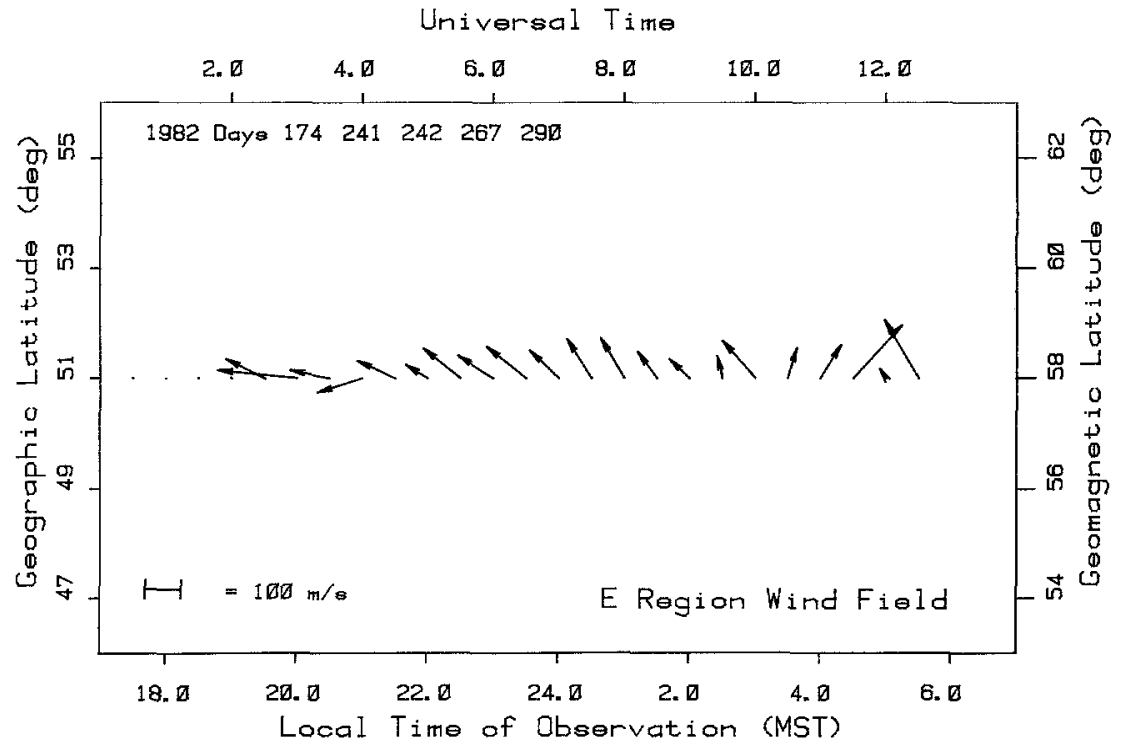

Fig. 3. The average neutral wind vector at Calgary during nights when the wind was PREDOMINANTLY POLEWARD: 22/23 June, 28/29 AuguSt, 29/30 August, 23/24 SEPTEMBER AND 16/17 OCTOBER.

and wind variable throughout the night. The average wind vectors for the 5 nights of predominantly northward flow are shown in Fig. 3. These vectors were obtained by first averaging the data from the four latitudes to obtain station average winds for each night, and then finding the mean vectors for the 5 nights (22/23 June, 28/29 August, 29/30 August, 23/24 September, $16 / 17$ October). Starting at 21.00 there was a northward component throughout the night, and between 19.00 and 03.00 there was also a westward component to the flow. The mean wind vectors had magnitudes that were typically about $100 \mathrm{~m} \mathrm{~s}^{-1}$. These were all moderately disturbed nights with a $K_{p}$ average for each night near 4.

The average wind field for the 10 nights (29/30 July, 30/31 July, 31 July/1 August, 4/5 August, 5/6 August, 7/8 August, 8/9 August, 12/13 August, 17/18 August, 30/31 August) of predominantly southward flow is shown in Fig. 4. The $K_{p}$ indices were typically about 3 which indicates these nights were somewhat quieter than those for predominantly poleward flow. The observations covered the period $22.00-04.00$ during which time the wind was almost due southward and fairly strong $\left(\geqslant 100 \mathrm{~m} \mathrm{~s}^{-1}\right)$, but only for latitudes North of Calgary. To the South the wind was variable in magnitude and direction, but certainly much smaller, and tended to be northward rather than southward. It is not possible to know whether there was a convergence of flow near the latitude of Calgary or alternatively whether two different altitude regions were being probed, higher to the North and lower in the South where the airglow source is expected to dominate during quieter periods.

Abreu et al. (1983) showed that under certain circumstances such as a large gradient in surface brightness from the South to North of a station, tropospheric scattering of the bright emission into the field of view of the instrument can contaminate the Doppler shift measurement. However, the possibility of tropospheric scattering in this case can be discounted because the lowest latitude data which are the most susceptible, did not show a large northward component.

Only 2 nights (29/30 September, 4/5 October) showed eastward winds after midnight, and then only for the two northern latitudes. The wind vector, of magnitude usually under $50 \mathrm{~m} \mathrm{~s}^{-1}$, rotated clockwise throughout the night from northwestward near 22.00 to due eastward in the late morning.

The final category, nights that showed no dominant wind pattern, is the largest. On some nights the wind vectors were highly variable in space and time, but on others there were short periods when the wind vectors were more ordered. An example of the latter situation is shown in Fig. 5. The magnitudes of the wind vectors were usually less than $100 \mathrm{~m} \mathrm{~s}^{-1}$ throughout the night with no apparent trend. The direction of the wind during parts of the night remained relatively constant 


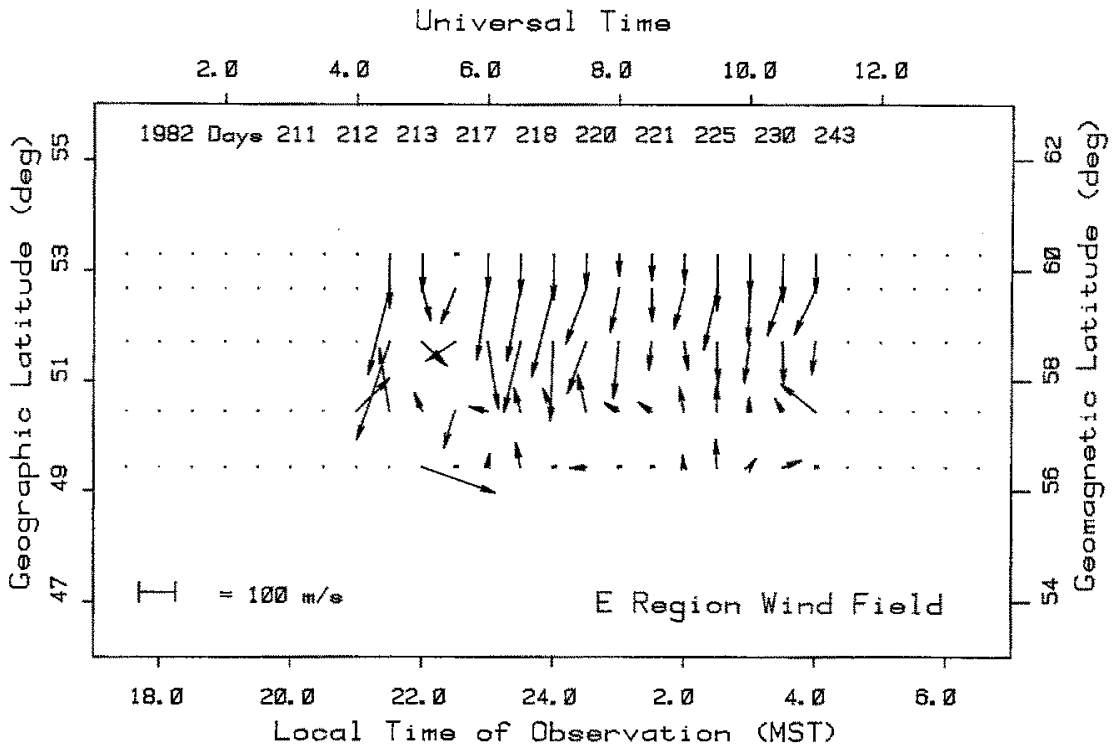

Fig. 4. ThE AVERAGE NEUTRAL HORIZONTAL WIND VECTORS FOR 10 NIGHTS OF PREDOMINANTLY EQUATORWARD Flow: 29/30 July, 30/31 July, 31 JULy/1 August, 4/5 August, 5/6 August, 7/8 AuguST, 8/9 AUGUST, $12 / 13$ AUGUST, $17 / 18$ AUGUST AND $30 / 31$ AUGUST.

for periods up to about $2 \mathrm{~h}$ over part of the observable wind field, but there was no obvious consistency from night to night. The absence of a dominant pattern is probably a consequence of weaker aurora during quieter magnetic conditions.

\section{DISCUSSION}

The neutral winds obtained for auroral heights during the four nights of disturbed magnetic conditions (Fig. 2) closely resemble the $F$-region winds measured

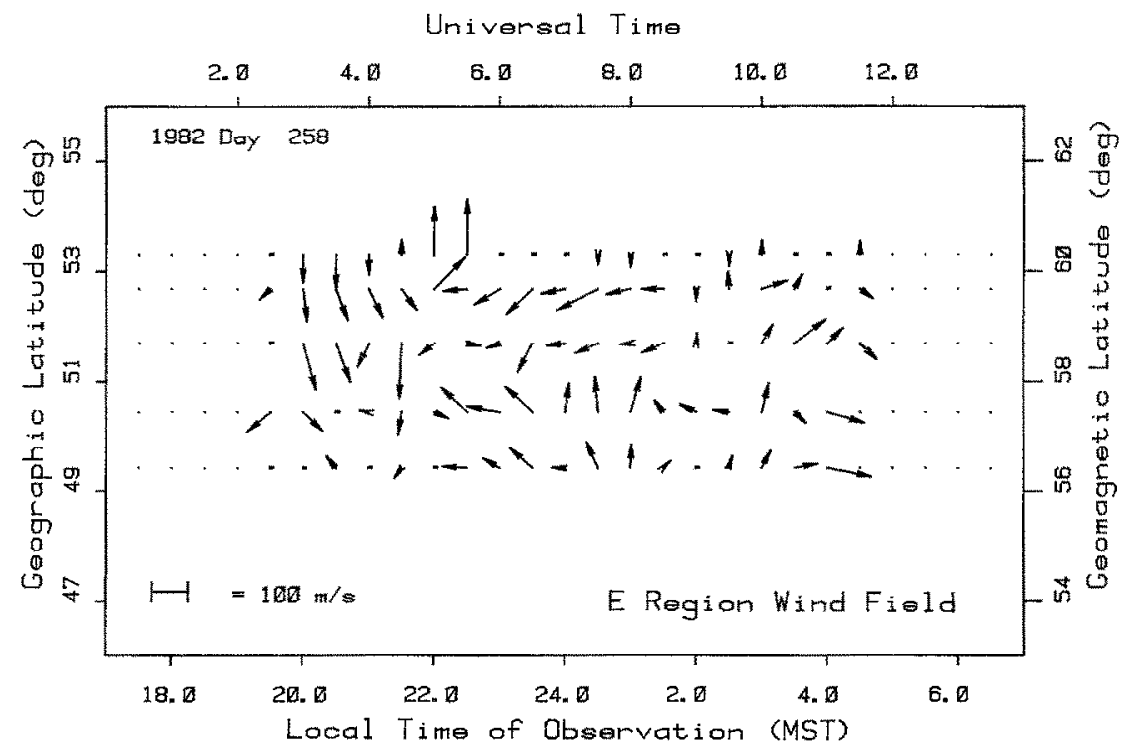

FIG. 5. AN EXAMPLE, 14/15 SEPTEMBER 1982, OF A NIGHT DURING WHICH THERE WAS CONSIDERABLE VARIATION OF THE WIND, BUT NO DOMINANT PATTERN. 
at Calgary during active periods (Meriwether, 1983). The $F$-region winds are stronger, often exceeding $300 \mathrm{~m}$ $\mathbf{s}^{-1}$ during these periods, but the direction is typically northwestward before midnight and equatorward during the morning hours. It is apparent that electric ficlds associated with the auroral conditions are effectively coupling the neutral gas motion in the $E$ and $F$ regions through ion drag. The fact that the magnitude of the $E$ region wind is smaller is a consequence of the larger collision frequency at lower altitudes.

The dominant role of the electric field in $E$-region neutral dynamics was demonstrated convincingly by Brekke et al. (1973) using the incoherent scatter radar facility at Chatanika. They measured the ion velocity in both the $E$ and $F$ regions. At the higher altitudes theionneutral collision frequency is much smaller than the ion gyrofrequency so they neglected the effects of ionneutral collisions and could then obtain the electric field from the expression $\mathbf{E}=\mathbf{v} \times \mathbf{B}$. They inserted this inferred value of $\mathbf{E}$ into the steady state momentum equation for ions in the $E$ region, and were able to calculate the height-averaged neutral velocity. These wind vectors varied throughout the night with speeds usually between 0 and $150 \mathrm{~m} \mathrm{~s}^{-1}$. The presence of a northward component of the electric field in the evening was associated with westward flow, while a southward component of the electric field that was observed in the morning was associated with eastward flow. Chatanika is in the region of strong convective ion flow near midnight on moderately quiet days because of its location ( $65^{\circ}$ geomagnetic latitude). It is then expected that a similar flow pattern would be observed at Calgary, $5^{\circ}$ equatorward, on highly disturbed days only. The observations at the two locations are in good qualitative agreement with this general picture, especially before midnight. After midnight the Chatanika results indicate that an eastward component of the neutral wind is a regular feature, whereas at Calgary an eastward component is rather rare (2 nights out of 75).

The fact that the magnitude of the Calgary winds during these very disturbed days was not very different from those inferred at Chatanika for moderate electric fields $\left(E \lesssim 35 \mathrm{mV} \mathrm{m}^{-1}\right)$ implies that the electric fields at Calgary were not unusually large either. Uncertainty in the altitude of the auroral emission, however, is an important consideration as well. If, on these 4 very disturbed nights (Fig. 2), the electron precipitation was very soft, the emitting region could be above $130 \mathrm{~km}$ where the reduced collision frequency would result in reduced impedance to the motion. If, on the other hand, the electron precipitation were hard, so that most optical emission came from the lower $E$ region where it is expected that the ion-neutral collision frequency exceeds the ion gyrofrequency, then the wind vector would be in the direction of $\mathbf{E}$ rather than of $\mathbf{E} \times \mathbf{B}$.

The wind patterns of Figs. 3 and 4 (poleward and equatorward winds all night respectively) do not agree with models and observations of lower thermospheric dynamics. The magnitude is much larger than has been obtained for prevailing winds in the $90-120 \mathrm{~km}$ region by various techniques (Wand, 1983; Manson et al., 1981 ; Vincent and Ball, 1981). Circulation models also predict small $\left(<20 \mathrm{~m} \mathrm{~s}^{-1}\right)$ meridional winds (Dickinson et al., 1981; Fuller-Rowell and Rees, 1980). A tidal explanation is also inadequate because measured amplitudes of the diurnal and semi-diurnal tides are relatively small, of the order of $20 \mathrm{~m} \mathrm{~s}^{-1}$, and the phases are incompatible (Manson et al., 1981; Wand, 1983). It therefore appears certain that the source of these patterns (Figs. 3 and 4) is related to auroral processes.

The most common characteristic of the observed winds is the variableness in space and time. A coherent pattern may be evident in small regions surrounded by what appears to be random wind vectors. A great deal of variation is what one might expect considering the many possibilities for small-scale generation of winds, e.g. particle heating, Joule heating, gravity waves. In some cases it is also possible that our assumption of a static wind pattern for a period of about 10-15 min was invalid.

\section{CONCLUSION}

In this paper we have demonstrated that $E$ region winds can he ohtained from measurements of the Doppler shift of the 5577 - $\AA$ emission of atomic oxygen, and that stable wind patterns do sometimes exist over several hundred kilometers so can be identified. From 75 nights of observations, we found four nights that exhibited a wind pattern similar to what is typically observed in the $F$ region over Calgary (using the 6300 - $\AA$ emission of atomic oxygen). This pattern cccurred on very disturbed days. On less magnetically disturbed days, there were two patterns identified: 10 nights during which the wind was equatorward all night; and 5 nights during which the wind was poleward all night. On most other nights there appeared to be no preferred directions. Magnitudes varied from about 30 $\mathrm{m} \mathrm{s}^{-1}$ up to about $200 \mathrm{~m} \mathrm{~s}^{-1}$, but wcre usually less than $100 \mathrm{~m} \mathrm{~s}^{-1}$.

The similarity of the wind directions during the 4 very disturbed nights and the $F$ region pattern, is evidence that the $E$ region winds during these nights are due to the same mechanism, ion-drag. Until we have simultaneous, wind measurements in both regions it is not possible to investigate the coupling further. 
Acknowledgements--This work was supported by grants from the Atmospheric Research Section of the National Science Foundation and NASA to the University of Michigan, and by operating grants from the Natural Sciences and Engineering Research Council of Canada to The University of Calgary.

\section{REFERENCES}

Abreu, V. J., Schmitt, G. A., Hays, P. B., Meriwether, J. W., Jr., Tepley, C. A. and Cogger, L. L. (1983) Atmospheric scattering effects on ground-based measurements of thermospheric winds. Planet. Space Sci. 31, 303.

Armstrong, E. B. (1969) Doppler shifts in the wavelength of the OI 6300 line in the night airglow. Planet. Space Sci. 17, 957.

Bates, D. R. (1979) On the proposals of Chapman and of Barth for $\mathrm{O}\left({ }^{1} \mathrm{~S}\right)$ formation in the upper atmosphere. Planet. Space Sci. 27, 717.

Biondi, M. A. (1984) Measured vertical motion and converging and diverging horizontal flow of the midlatitude thermosphere. Geophys. Res. Lett. 11, 84.

Brekke, A., Doupnik, J. R. and Banks, P. M. (1973) A preliminary study of the neutral wind in the auroral $E$ region. $J$. geophys. Res. 78, 8235 .

Burnside, R. G., Herrero, F. A., Meriwether, J. W. and Walker, J. C. G. (1981) Optical observations of thermospheric dynamics at Arecibo. J. geophys. Res. 86, 5532.

Cocks, T. D. and Jacka, F. (1979) Daytime thermospheric temperatures, wind velocities and emission intensities derived from ground based observations of the OI $630 \mathrm{~mm}$ airglow line profile. J. atmos. terr. Phys. 41, 409.

Dickinson, R. E., Ridley, E. C. and Roble, R. G. (1981) A threedimensional general circulation model of the thermosphere. J. geophys. Res. 86, 1499.

Evans, J. V. (1978) Incoherent scatter contributions to studies of the dynamics of the lower thermosphere. Rev. Geophys. Space Phys. 16, 195.

Forbes, J. M. and Garrett, H. B. (1979) Theoretical studies of atmospheric tides. Rev. Geophys. Space Phys. 17, 1951.

Fuller-Rowell, T. J. and Rees, D. (1980) A three-dimensional time-dependent global model of the thermosphere. $J$ Atmos. Sci. 37, 2545.

Hays, P. B., Killeen, T. L. and Kennedy, B. C. (1981) The Fabry-Perot interferometer on Dynamics Explorer. Space Sci. Inst. 5, 395 .

Hays, P. B. and Roble, R. G. (1971) Direct observations of thermospheric winds during geomagnetic storms. $J$. geophys. Res. 76, 5316 .
Heppner, J. P. and Miller, M. L. (1982) Thermospheric winds at high latitudes from chemical releases. J. geophys. Res. 87, 1633.

Hernandez, G. (1982) Vertical motions of the neutral thermosphere at midlatitude. Geophys. Res. Lett. 9, 555.

Hernandez G. and Roble, R. G.(1976) Direct measurements of thermospheric winds and temperatures, 1 . Seasonal variations during geomagnetically quiet periods. $J$. geophys. Res. 81, 2065.

Hines, C. O. (1960) Internal atmospheric gravity waves at ionospheric heights. Can. J. Phys. 38, 1441.

Jacka, F, Bower, A. R. D. and Wilksch, P. A. (1979) Thermospheric temperatures and winds derived from ol $630 \mathrm{~nm}$ night airglow line profiles. $J$, atmos. terr. Phys. 41, 397.

Killeen, T. L., Hays, P. B., Spencer, N. W, and Wharton, L. E. (1982) Neutral winds in the polar thermosphere as measured from Dynamics Explorer. Geophys Res. Lett. 9, 957.

Manson, A. H., Meek, C. E. and Gregory, J. B. (1981) Winds and waves (10 min-30 days) in the mesosphere and lower thermosphere at Saskatoon $\left(52^{\circ} \mathrm{N}, 107^{\circ} \mathrm{W}, L=4.3\right)$ during the year, October 1979 to July 1980. J. geophys. Res. 86, 9615.

Meriwether, J. W., Jr. (1983) Observations of thermospheric dynamics at high latitudes from ground and space. Radio Sci. 18, 1035.

Meriwether, J.W.,Jr, Tepley, C.A.,Price,S.A.,Hays, P.B. and Cogger, L. L. (1983) Remote ground-based observations of terrestrial airglow emissions and thermospheric dynamics at Calgary, Alberta, Canada. Opt. Eng. 22, 128.

Rees, M. H. (1975) Magnetospheric substorm energy dissipation in the atmosphere. Planet. Space Sci. 23, 1589.

Rees, D., Greenaway, A. H., Gordon, R., McWhirter, I., Charleton, P. J. and Steen, \&. (1984) The Doppler imaging system: Initial observations of the auroral thermosphere. Planet. Space Sci. 32, 273.

Tepley, C. A., Burnside, R. G., Meriwether, J. W., Jr., Hays, P. B. and Cogger, L. L. (1984) Spatial mapping of the thermnspheric neutral wind field. Planet. Space Sci. 32, 493.

Vincent, R.A. and Ball, S. M.(1981) Mesospheric winds at lowand mid-latitudes in the southern hemisphere. $J$. geophys. Res. 86, 9159.

Wand, R. H. (1983) Seasonal variations of lower thermospheric winds from the Millstone Hill incoherent scatter radar. J. geophys. Res. $\mathbf{8 8}, 9227$. 